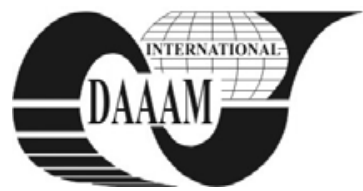

\title{
ASSESSMENT OF HAND-TRANSMITTED VIBRATION DURING WORK WITH CHAIN SAW
}

\author{
DADO, M[iroslav]; HNILICA, R[ichard]; KOVAC, J[an] \& KUCERA, M[arian]
}

\begin{abstract}
The chain saw represents significant source of occupational exposure to hand-transmitted vibration. The aim of this paper is to provide a review of vibration risk assessment process with focus on two types of approaches for exposure estimation: database support and direct field measurements.
\end{abstract}

Key words: vibration, risk assessment, exposure, control measures, chain saw

\section{INTRODUCTION}

The importance of managing health and safety (H\&S) within forestry has increased in significance over recent years. It is because of the increasing responsibility placed on employers as a result of growing H\&S legislation, with which they must comply. The main legislation in area of occupational vibration are Government Regulation No. 416/2005 Coll. on the minimum health and safety re-quirements regarding the exposure of workers to the risks arising from vibration and Government Regulation No. 629/2005 Coll. which make it a legal requirement for employers to identify, risk-assess, and appropriately manage workers exposure to both whole-body vibration and hand-arm vibration. Whole-body vibration occurs when the human body is supported on a surface which is vibrating, e.g. in all forms of timber transport and when working inside some forest machine (e.g. forwarder, universal wheeled tractor, forest wheeled tractor). Hand-arm or handtransmitted vibration occurs when the vibration enters the body through the hands e. g. in various works with chain saw where rotating move transmits are held by the hands or fingers. Because these two kinds of vibration exposure are entirely different (in terms of sources, health effects, measurement, risk control methods, etc.), it is solely the aspect of hand-transmitted vibration with which this paper is concerned.

\section{HEALTH EFFECTS OF HAND-TRANSMITED VIBRATION}

There are many different effects of oscillatory motion on the body and many variables influencing each effect. The variables may be categorized as extrinsic variables (those occurring outside the human body - vibration magnitude, frequency, direction, input position, duration) and intrinsic variables (variability that occurs between and within people - body posture, position, size and weight, age, gender, fitness) (Mansfield, 2004).

Prolonged and regular exposure of the fingers or the hands to vibration or re-peated shock can give rise to various signs and symptoms of disorder. The precise extent and interrelation between the signs and symptoms are not fully understood, but five types of disorder may be identified (see Table 1). The various disorders may be interconnected: more than one disorder can affect a person at the same time and it is possible that the presence of one disorder facilitates the appearance of another. The onset of each disorder is dependent on several variables, such as the vibration characteristics, the dynamic response of the fingers or hand, individual susceptibility to damage, and other aspects of the environment (Griffind, 2004). The terms vibration syndrome or hand-arm vibration syndrome (HAVS) are sometimes used to refer to one or more of the effects listed in Table1.

\begin{tabular}{|l|l|}
\hline Type & \multicolumn{1}{|c|}{ Disorder } \\
\hline A & Vascular disorders \\
\hline B & Neurological disorders \\
\hline C & Bone and joint disorders \\
\hline D & Muscle disorders \\
\hline E & Other general disorders (e.g. central nervous system) \\
\hline
\end{tabular}

Tab. 1.Types of Disorders Associated with Hand-Transmitted Vibration Exposures

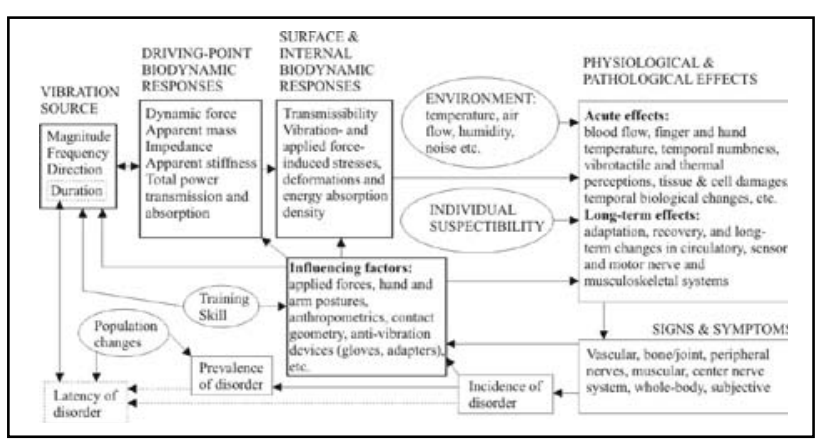

Fig. 1. A conceptual model for influencing cause-effect relationships for HTV exposure (Dong, 2006)

\section{RISK ASSESSMENT PRINCIPLE}

The purpose of the hand-arm vibration risk assessment is to enable to make a valid decision about the measures necessary to prevent or adequately control the risks from exposure of workers to hand-arm vibration. The risk assessment should:

- identify where there may be a risk from hand-arm vibration,

- $\quad$ estimate worker's exposures and compare them with the exposure action va-lue (EAV) and exposure limit value (ELV),

- $\quad$ identify the available risk controls.

Source of exposure to hand-transmitted vibration is chain saw usually transmitted through the handles of chain saw.

In descriptive terms, the EAV is a level of daily vibration exposure that if reached (or exceeded) requires specified (risk control) action to be taken to reduce that risk, while the ELV is a level of daily exposure which must not (other than in very specific circumstances) be exceeded. EAV and ELV are defined in terms of an aver-age vibration magnitude (expressed as acceleration), over a typical working shift of eight hours. The daily exposure limit value standardised to an eight-hour 
reference period is $5 \mathrm{~m} . \mathrm{s}^{2}$ and the daily exposure action value standardised to an eight-hour reference period is $2,5 \mathrm{~m} . \mathrm{s}^{2}$. This means a worker will reach a level of exposure equivalent to the action value, if they are exposed to an average vibration magnitude of 2,5 m.s ${ }^{2}$ continuously for eight hours. So exposure to an average magnitude greater than this will mean they reach the EAV sooner than in eight hours. Conversely, if they are exposed to a magnitude lower than $2,5 \mathrm{~m} . \mathrm{s}^{2}$, then they can be exposed to that lower average level for more than eight hours before reaching the EAV. These concepts apply equally to the ELV, other than the fact that average vibration magnitude applying to the ELV is double that of the EAV.

\section{CALCULATION OF DAILY EXPOSURES}

Hand-arm vibration risk is based on the frequency-weighted acceleration total value, given by the root-sum-of-squares of the frequency-weighted acceleration from the three orthogonal axes, $x, y$ and $z$. For hand-transmitted vibration, the frequencies thought to be important range from about $8 \mathrm{~Hz}$ to $1000 \mathrm{~Hz}$. However, because the risk of damage to the hand is not equal at all frequencies a frequency-weighting is used to represent the likelihood of damage from the different frequencies. As a result, the weighted acceleration decreases when the frequency increases. For hand-arm vibration, only one frequencyweighting curve is used for all three axes.

In general, there exist two approaches to obtain data about vibration magnitude. The first approach is to use data from databases available on the web:

- The KARLA database (http://www.las-bb.de/karla/),

- The Centralised European Hand-arm Vibration Database (http://umetech.niwl.se/eng/havhome.lasso),

- The HAVTEC database (http://www.operc.com/havtec/).

When using published vibration data it is good practice to try to compare data from two or more sources (Edwards \& Holt, 2007). Sometimes it may not be possible to obtain adequate information from aforementioned databases. In this case it will be necessary to make measurements of vibration in the workplace. Measurements at workplaces are very complex and often disturb the working process. Hand-arm vibration measuring equipment should comply with the STN EN ISO 8041:2005 and measurement should be perform in accordance with STN EN ISO 5349-1:2001 and STN EN ISO 5349-2:2001. The vibration exposure for the daily use of a process or tool can be calculated from a magnitude and duration, using this equation:

$$
A(8)=\mathrm{a}_{m v} \sqrt{\frac{T}{T_{0}}}
$$

where $a_{\mathrm{hv}}$ is the vibration magnitude (in $\mathrm{m} / \mathrm{s}^{2}$ ), $T$ is the daily duration of exposure to the vibration magnitude $a_{\mathrm{hv}}$ and $T_{0}$ is the reference duration of eight hours. If a worker is exposed to vibration from only one source (a single tool or work process) the $A(8)$ value described above represents his or her daily exposure. However, if a person is exposed to more than one source of vibration (perhaps because they use two or more different tools or processes during the day) then a partial vibration exposure is calculated from the magnitude and duration for each one. Having determined the partial vibration exposure value for each vibration source to which a person is exposed, the overall daily vibration exposure can be calculated using this equation:

$$
A(8)=\sqrt{A_{1}(8)^{2}+A_{2}(8)^{2}+A_{3}(8)^{2}+\ldots .+A_{n}(8)^{2}}
$$

where $A_{1}(8), A_{2}(8), A_{3}(8)$, etc. are the partial vibration exposure values for the different vibration sources.

\section{CONCLUSION}

The most effective way to prevent vibration reaching worker's hands is to avoid using processes which require workers to hold vibrating surfaces. When the use of vibrating equipment is unavoidable, it is often possible to control the vibration transmitted to the hand. The greater the gripping or pushing forces exerted through the hand onto the vibrating surface, the more efficiently the vibration passes into the user's hand and arm (Welcome et al., 2004). These forces may be required to support the tool or workpiece, to control or guide the machine, or to achieve high working rates. The actual forces applied can be greater than is essential for efficient work because of incorrect equipment selection, inadequate maintenance, insufficient training or poor work station design (Rakheja et al., 2002). When the vibration magnitudes have been reduced to a minimum, further reduction in exposure can be achieved by limiting the time for which employees are exposed to a vibration hazard. Job rotation or other management techniques can help to keep times down.

The result of recent knowledge about chain saws is that work with them is hazard and has negative influence on the health of workers, there are mainly occupational illnesses caused by vibrations a chain saw. A chain saw must be designed to create the lowest possible level of vibrations. Limit these effects has an impact on technical, organizational and technological interventions to be used for preventive measures. Therefore, leading manufacturers of chain saws have introduced various technical measures, which have the effect of reducing vibration. Technical measures to serve its target, it made a series of measures in the maintenance of chain saws.

\section{ACKNOWLEDGEMENTS}

The paper is based on work performed under research contract no. 1/0403/11 „Chain saws research of technical parameters regarding to ergonomics and ecology of work " of the Scientific Agency of Ministry of Education of Slovak republic and the Slovak Academy of Science whose support is gratefully acknowledged.

\section{REFERENCES}

Dong, R. G. et al. (2006). Recent Advances in Biodynamics of Human Hand-Arm System. Industrial Health, Vol.43, No.3, 2006, pp. 449-471, ISSN 0019-8366

Edwards, D. J.; Holt, G.D. (2007). Risk-assessing hand-arm vibration exposure: The role of HAVTEC. Construction Information Quarterly, Vol. 9, No. 2, 2007, pp. 74-79, ISSN 1469-4891

Griffin, M. J. (2004). Handbook of Human Vibration. $3^{\text {th }}$ edition, Elsevier Academic Press, London, 2004, ISBN 978-0-12-303041-2

Mansfield, N. J. (2004). Human response to vibration. CRC Press, London, 2004, ISBN 041528239X

Rakheja, S. et al. (2002). A Comparison of Biodynamics Models of the Human Hand-Arm System for Applications to Hand-Held Power Tools. Journal of Sound and Vibration, Vol. 249, No.1, 2002, pp. 55-82, ISSN $0022-$ $460 \mathrm{X}$

Welcome, D. E. et al. (2004). Relationship Between Grip, Push and Contact Forces Between the Hand and a Tool Handle. International Journal of Industrial Ergonomics, Vol. 34, No.6, 2004, pp. 507-518, ISSN 0169-8141 